ALTERIDADES, 2019, 29 (58): Págs. 61-72 www.doi.org/ 10.24275 /uam / izt/dcsh / alteridades / 2019v29n58/Gallardo

\title{
Cuerpos habitados Reflexiones sobre la corporalidad entre los otomíes orientales*
}

\author{
Habitable bodies \\ Reflections on corporality among eastern Otomi
}

PATRICIA GALLARDO ARIAS**

\begin{abstract}
Based on ethnographic material obtained from 2006 to 2018 among Otomis of the eastern mountain range of Hidalgo in Mexico, this research aims to untangle the meanings regarding native concepts to refer to the body and its contents. These categories include beings that are recognized as people, as well as those identified as gods, spirits, and nahuales. The conclusion is that the body contains in itself the notions of transformation, fabrication, force, instability, balance, sickness and potentiality; thereby, for eastern Otomis the body is not something concluded, but rather it is in the process of construction.
\end{abstract}

Key words: Otomi, body, content, construction, transformation

\section{Resumen}

Basado en el material etnográfico realizado de 2006 a 2018 entre los otomíes de la sierra oriental de Hidalgo en México, este trabajo busca desentrañar los significados sobre los conceptos nativos para designar el cuerpo y sus contenidos. Dichas categorías incluyen a seres que se reconocen como personas, y también a los que se identifican como dioses, espíritus y nahuales. Se concluye que la idea del cuerpo contiene en sí misma las nociones de transformación, fabricación, fuerza, inestabilidad, equilibrio, enfermedad y potencialidad; por ende, para los otomíes orientales el cuerpo no es algo terminado sino en proceso de construcción.

Palabras clave: otomíes, cuerpo, contenidos, construcción, transformación

\section{Introducción}

$\mathrm{E}$ 1 cuerpo como tema ha sido tratado por los investigadores a partir de 1920, los trabajos de la escuela francesa proporcionan ejemplos de estudios que relacionan al cuerpo con un análisis de carácter simbólico, religioso y cultural (Mauss, 1985 [1936]). En estos textos llaman la atención aspectos del cuerpo que llevan a su inestabilidad natural (Lévy-Bruhl 1996 [1927]: 8). En años recientes, la simbolización del cuerpo ha puesto de relieve cuestiones tan difíciles de explicar como la imagen de lo femenino, de la sexualidad, de la relación persona-cuerpo-cosmos y, sobre todo, de la dinámica salud-enfermedad.

\footnotetext{
* Artículo recibido el 13/12/18 y aceptado el 30/04/19.

** Instituto Nacional de Antropología e Historia, Dirección de Etnohistoria. Av. Paseo de la Reforma y Calzada Gandhi s/n, col. Chapultepec Polanco, Miguel Hidalgo, 11560, Ciudad de México <patriciagallardo1@hotmail.com>.
} 
Hoy se debaten entre los antropólogos asuntos como la relación cuerpo-cultura, cuerpo-objeto culturalizado o cultura-sujeto corporalizada. Han sido discutidos a la luz de nuevos datos etnográficos y posturas teóricas, donde se apoya la idea de que la cultura se halla presente de manera simultánea en la estructura social y en las funciones mismas del cuerpo, al contrario de las propuestas que respaldan la noción de que el cuerpo es sólo una representación de la cultura (Galinier, 1990). Como Viveiros de Castro menciona acerca del trabajo de Galinier sobre los otomíes orientales,

se trata de mostrar cómo la cultura es una función del cuerpo, que no existiría antes y fuera de éste, en un reino transcendente de reglas y de significaciones incorporales. El cuerpo deja de ser así una representación de la cultura -en el doble sentido de expresarla y de ser algo que la representa- para pasar a ser la cultura misma, su condición de posibilidad y su modo de realidad. Inmanencia del sujeto al cuerpo [Viveiros de Castro, 2009: 48].

De allí la importancia de la subjetividad para el análisis de las concepciones sobre el cuerpo, ya que se puede observar e interpretar por medio del mundo interno de los sujetos (Habermas, 1987). La cultura aparecería como acumulación social de significados que se van actualizando, pero los significados acumulados tienen una persistencia mayor y una autonomía relativa de las prácticas, ya que la realidad social puede ser pensada en diferentes niveles de abstracción, por ejemplo, lo que hacen los ritualistas y lo que hacen los devotos (Bourdieu, 2007: 224-225, 148-149).

Lo subjetivo da sentido a la cultura, compuesta de elementos cognitivos, valores, estética, emociones, que se expresan en discursos-rezos, cantos y mitos y en manifestaciones estéticas. Los significados se generan dentro de límites espaciales y temporales (Bourdieu, 2007: 101) y se vinculan con significados acumulados socialmente. Al ser el sujeto resultado de los modos de subjetivación que cambian histórica y culturalmente, cualquier cambio en las prácticas subjetivas tiene un efecto en la formación del sujeto, por consecuencia, nuevas prácticas implican una transformación debido a que se introduce una nueva forma de subjetivación (Foucault, 1991, 1992a, 1992b). Es por ello que no todo nivel de las prácticas es captado significativamente por los sujetos, éstos pueden estar o no conscientes de esos niveles y sin embargo sufrir sus efectos (Bourdieu, 1997: 25). Asimismo, en la cultura, como sistema de normas y valores y como acumulación de significados, no todos los significados tienen que ser normativos, pueden ser morales, estéticos y cognitivos.

De forma que las vivencias expresadas a través de signos y organizadas en un sistema de significados son reflexión sobre la vivencia, pero no la vivencia misma (Habermas, 1987). De allí que todos aquellos aspectos que se destacan como elementos subjetivos son importantes para analizar las nociones sobre el cuerpo, "ya que permite comprender qué hacen los sujetos con lo que son, con lo que tienen y con lo que pueden, en interacción con las formaciones sociales y culturales en un contexto determinado" (Cabrera, 2014: 189).

Uno de los elementos principales de la visión del mundo indígena en México es la noción que se tiene del cuerpo y del conjunto de sustancias que lo animan (López Austin, 1996: 147). ${ }^{1}$ Al abordar el problema entre los otomíes orientales la noción de persona se concibe como una prolongación del cuerpo, es un sistema en el cual todo está comunicado a través de sustancias que circulan de los pies a la cabeza llevando vida y fuerza a todos los órganos; si estas sustancias se separan de la persona y del cuerpo, se detiene la vida. De esta forma, los seres humanos se encuentran habitados por energías que fluyen y les dan vida; estas sustancias están contenidas en el cuerpo humano, donde se ubica el ser, la conciencia, los sueños, el conocimiento y el pensamiento.

El cuerpo aparece como un microcosmos, donde se establece una relación estrecha entre el universo y el hombre. Siendo el cuerpo un microcosmos unido al macrocosmos, con el cual se relaciona. Como advierte Galinier: "el cuerpo no es simplemente un modelo de representación de puntos particulares del universo. 'Es' el mundo" (2009: 86). El cuerpo, como menciona Turner, "es siempre considerado como un lugar privilegiado para la comunicación de las gnosis, del conocimiento místico sobre la naturaleza de las cosas y el modo como éstas llegan a ser lo que son". El universo, en algunos casos, puede ser descrito y observado como un gran cuerpo humano; las partes visibles del cuerpo pueden ser utilizadas para figurar las facultades invisibles, tales como la razón, la pasión y el conocimiento, en otros casos, "las diferentes partes del orden social aparecen dispuestas según la forma del paradigma anatómico humano" (Turner, 1980: 119).

Esta relación se ha prefigurado a través de explicaciones míticas mantenidas por el conocimiento chamánico, su concepción adquiere tal característica de realidad que, para ser curandero, en su iniciación, el cuerpo de éste es sometido a varias pruebas sacrificiales

\footnotetext{
1 Para López Austin, "fuerzas, almas y dioses tienen una primera característica común: son imperceptibles para los seres
} humanos. Como el viento, como la noche, son invisibles e impalpables" (1996: 147). 
con una comprensión cósmica. Este sometimiento del cuerpo a las ritualizaciones más diversas se hace con el fin de canalizar la energía primordial. En los seres humanos, esta energía actúa proporcionándole vitalidad al cuerpo, al elemento material o tangible de la persona, garantizando la cohesión entre éste y el espíritu o alma, elemento menos tangible del individuo, constituido por una materia menos densa.

\section{Los otomíes de la sierra de Tutotepec}

El municipio de San Bartolo Tutotepec se localiza en la sierra hidalguense al sur de la Huasteca. Colinda al norte con el estado de Veracruz, al sur con Tenango de Doria, al este con Huehuetla y al oeste con Agua Blanca y el estado de Veracruz. Cuenta con 18000 habitantes que se distribuyen en 170 localidades. La mayoría de la población es bilingüe otomí-español. ${ }^{2}$

La variante otomí de la sierra oriental cuenta con 13 vocales (Echegoyen y Voigtlander, 2007), ${ }^{3}$ de las cuales nueve son orales y cuatro nasales, representadas con diéresis <ä>. Asimismo, cuenta con 20 consonantes y tres tonos: alto, representado con un acento agudo <á>; bajo, representado con un acento grave <à>; y ascendente, representado con un acento circunflejo inverso <ă> (Gallardo Arias, 2012).

En el otomí se identifican dos tipos de palabras: las raíces (sustantivos y verbos) y los clíticos, que son palabras funcionales que permiten la flexión y derivación morfológica. En los nombres encontramos la forma ya para indicar el plural y la forma ná para el singular, que se traduce como "éste". También se encuentra la utilización de ná, clítico que señala el modo infinitivo y provee la forma sustantiva del verbo. Ambos pueden presentarse sufijados al final del sustantivo. Si es utilizado al principio de la oración, ná indica que el hablante se encuentra en un nivel inferior; también se usa como marcador de números ordinales (Echegoyen y Voigtlander, 2007: 257). El clítico ná se emplea de manera recurrente durante el discurso ritual, en términos relacionados con las deidades, ${ }^{4}$ con los rituales y con sus oficiantes, por lo cual puede afirmarse que dicho clítico corresponde al nivel del discurso. En este caso, los hablantes se desligan de la información que están pronunciando, traduciéndose como "se dice", "dicen", "según dicen”. Pero no es que los otomíes señalen que lo que se enuncia no "sea real"; al contrario, se dice que la palabra tiene en sí misma una eficacia. Al pronunciar los nombres de algunas de las deidades se les está dando poder y presencia; por consiguiente, los otomíes son cuidadosos cuando "llaman" a objetos, sujetos y deidades. De este modo, cuando se escribe Zìthü'na se traduce como "diablo" o "ese que dicen diablo"; de igual manera, cuando se habla de bădi'na se traduce como "el que sabe" o "ese que dicen que es brujo".

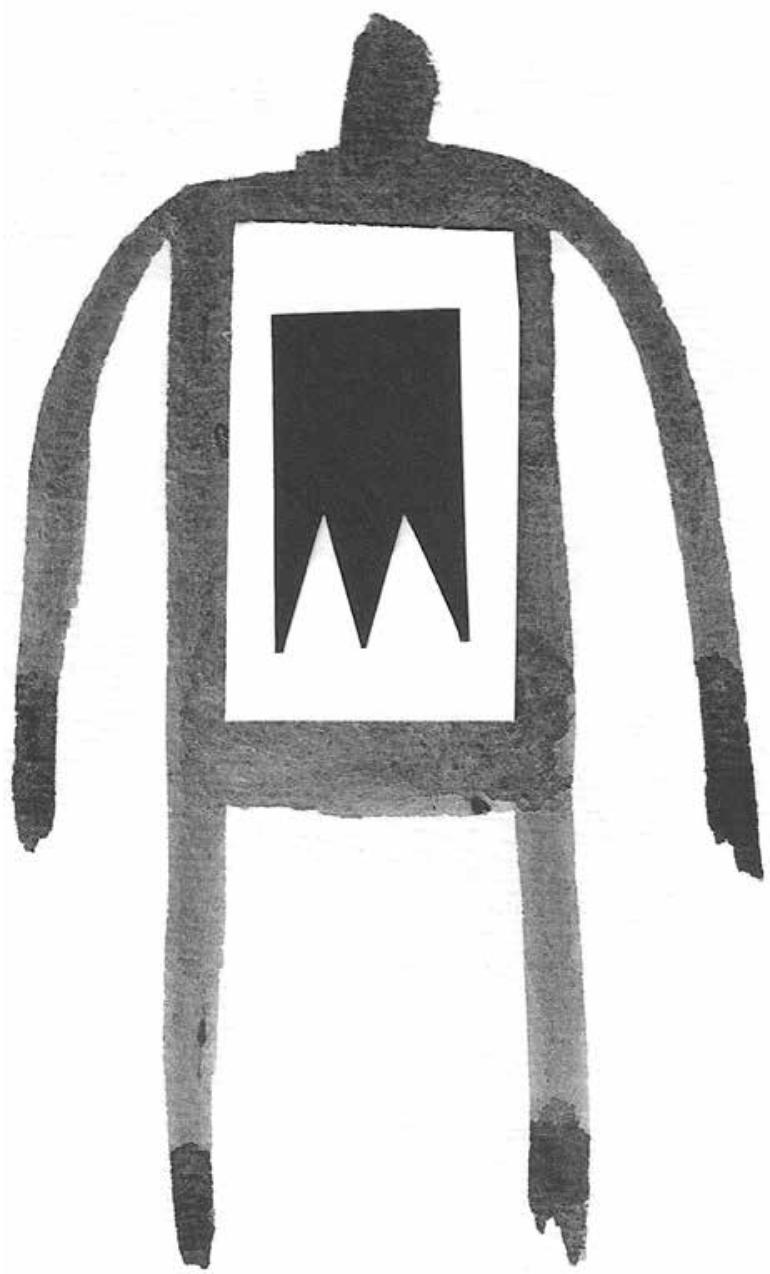

2 El otomí pertenece a la familia lingüística otopame. Esta familia se dividía en dos grupos: el primero conformado por los otomíes, mazahuas y matlatzincas, a quienes se definió como agricultores, y el segundo integrado, por un lado, por los pames, y, por el otro, por los chichimecas, tipificados como nómadas.

3 Tratando de formalizar el sistema escrito, en esta investigación me apoyé en el Diccionario yuhú. Otomí de la Sierra Madre Oriental. Estados de Hidalgo, Puebla y Veracruz, preparado por Artemisa Echegoyen y Catherine Voigtlander, debido a que las variantes de la lengua manejadas en este artículo son las más cercanas al texto de Echegoyen y Voigtlander.

4 En este trabajo se utilizará el término deidades para designar a los seres a los cuales los otomíes les realizan diversos rituales. Las deidades tienen la capacidad de hacer, de actuar y de ser. El término otomí para designar la personalidad de las deidades es xón dùxxki, que se traduce como delicado y sagrado, aunque tiene otras acepciones, como las de peligroso y caprichoso. 
No todas las personas pueden acceder a la comunicación directa con las deidades; para ello recurren a los especialistas denominados bădi'na, por ser los únicos capaces de hablar el lenguaje que entienden éstas, que, además del rezo, alude a sonidos de campanas, silbatos y respiraciones muy sonoras. La palabra otomí para designar a estos especialistas muestra con mayor detalle lo que se entiende por ellos: hombres y mujeres que saben del ritual, de los mitos, del costumbre, además de curar.

Los ámbitos productivos en los que se mueven los otomíes de la sierra son el trabajo agrícola destinado al autoabasto y al mercado, el trabajo asalariado, y habría que agregar que los especialistas rituales cobran por sus servicios. La sierra se percibe como un lugar peligroso, esta apreciación tiene una base real, ya que lo accidentado del lugar, la falta de una infraestructura adecuada y la pobreza extrema en la que subsisten los otomíes crean circunstancias que afectan la salud y el acceso a mejores condiciones de vida, así como el robo, las riñas provocadas por el alcoholismo y, en consecuencia, la desesperación de los individuos. Por tanto, los otomíes viven pensando que en cualquier momento ocurrirá una desgracia: peleas, muerte, accidentes como caídas, encuentro en el monte con animales peligrosos, con las deidades, que provocarán que la persona agarre un "aire", pierda el "espíritu" y caiga enferma; este temor se acentúa durante ciertos rituales. No obstante, los otomíes saben que las deidades son de algún modo volubles, no se puede predecir cómo actuarán, ni cuándo lo harán, por eso son "delicadas", pero ellos siguen tratando y refuerzan las ofrendas y los rituales.

En el transcurso del año los otomíes realizan diferentes rituales. En febrero o marzo se hace el carnaval que está dedicado al señor de los muertos, se le pide a él y a sus compadres: los viejos que no traigan desgracias, que el maíz crezca y que las aguas vengan; después, en la época de secas (abril y mayo) se llevan a cabo los rituales denominados costumbres (Máte), se va a los cerros, a las cuevas y grutas, iglesias de origen colonial y algunos sitios de origen prehispánico, donde hay montículos. El costumbre se hace principalmente para las deidades de la fertilidad, o sea todas las semillas, para los dioses del agua: señor sirena, señora del agua y la campana, para la tierra y los cerros.

En todos los rituales se recorta en papel a las deidades y se hacen "camas" donde se colocan los papeles, algunas de las figuras se visten y depositan en cuevas y grutas, otras en el "monte", en los montículos prehispánicos, en el fogón casero; también se recortan las entidades anímicas que dan vida y habitan a los humanos, éstas se entregan al portador; además se recorta a los habitantes de la noche, mujeres que viven en las casas que son dueñas de los temazcales, el señor de la noche que deambula por la sierra durante la oscuridad, asimismo, a las deidades de la muerte se les coloca en envoltorios llamados tǒnts'i o limpias. Las figuras de papel recortado se denominan nzáki, son lo sagrado o Màká, de esta manera, si se hace la fuerza del agua se le dice: nzáki Màká Déhe o fuerza de la sagrada agua. Existen características específicas para cada una de las figuras de papel recortado, se colocan de cierta forma, número y por género, como a la gente, se les da de fumar, beber y comer, además de que se les sacraliza con la sangre de pollos y se les activa abriendo los pequeños agujeros que contiene cada figura, esto es: en el centro de la figura hay un agujero: $m b \underline{u} \underline{i}$, "el corazón" de la deidad, los especialistas abren el corazón y la boca para que la deidad se active. A todos ellos se les ofrenda comida, incienso, refrescos, tabaco, café, refino, cervezas, flores y veladoras; el término en otomí para la ofrenda es 'bóts'e, que se traduce como ofrecimiento y sacrificio. Aunque los preparativos para el ritual se realizan durante el día y a veces durante varios días, todo ritual otomí comienza por la noche con tǒnts'i (ofrenda para las deidades del "lugar de los muertos"), el especialista les habla, les invita cigarro, refino, pollo y café.

"Los que saben", y a bädi, son, pues, los encargados de dirigir el ritual, de representar, manejar y hacer que fluya la fuerza-energía de las deidades y llevarlas a los rituales para que se les rinda culto. Ellos son los únicos capaces de dar una explicación, un lugar a cada cosa, cada elemento, cada situación, cada emoción y de dar coherencia a sus actos y a los de otros dentro de su mundo.

Para los otomíes, xímhăi (mundo-universo) se encuentra en toda la sierra, lo conforman montes, bosques, peñas, cuevas, grutas, cerros, ríos, arroyos y pueblos, aquí es donde habitan hombres y deidades. En Màhëts'i ("donde está la luz") están "las antiguas", cuyos atributos se hallan asociados con la fertilidad; se tienen a las deidades del agua, el fuego, la tierra, el señor del monte, del maíz, del frijol. "Las antiguas" son pequeñas piezas arqueológicas que se encuentran en la sierra; estas figurillas no son compradas y en algunos casos son heredadas de generación en generación entre los especialistas. En Nídu'na (el lugar de los muertos) se encuentra Zìthü (reverenciado muerto), además de este término recibe varios nombres dependiendo del contexto ritual; por ejemplo, durante el carnaval los disfrazados le llaman mbáre, "el compadre", y también se le denomina ya ndò ("el viejito" pero con un sentido reverencial); en tanto, durante los rituales de costumbres se le nombra ts'utabi 
(delegado o juez), término con el cual los otomíes hacen énfasis en el poder que tiene para conceder justicia y favores, asimismo, remite a que él es quien manda en el lugar de los muertos. Hay dos nombres más que se le dan a Zìthü'na: mbójó y désna, términos utilizados para designar a los mestizos, a la gente que viene de la ciudad, y que en el caso específico del "señor de los muertos" hace referencia a su condición privilegiada con respecto al resto de los otomíes, porque se piensa que la gente de la ciudad tiene una mejor situación económica. Asimismo, según Boilés, y como mencionan hoy los otomíes, Zìthü'na "no es sólo el gobernante de los muertos, sino que también lo es de la mitad inferior del cuerpo por lo que controla las funciones sexuales" (Boilés, 1971: 557-558). Sin embargo, el nombre más utilizado en la sierra es Dàmánts'ó o “el malo". En el lugar de los muertos, además de Zìthü, los otomíes señalan que ya ts'ónthï ner ya ndáhï habitan allí. Ya ndáhï son muertos no "completados", individuos que se portaron mal en vida, por lo cual cuando murieron fueron enviados a acompañar a Zìthü.

Todas las fuerzas que habitan el ximhăi otomí son seres con una "potencia" que se ha desarrollado en acto por lo que son más fuertes, pueden favorecer a los humanos aunque también pueden enviarles desgracias si no se les trata con el debido cuidado; pueden tener los mismos defectos y cualidades que hombres y mujeres. Pero además controlan el cuerpo, los deseos, la voluntad y el pensamiento humano. En síntesis, ximhăi está habitado por diferentes clases de seres: los hombres y las mujeres (ya Jä'i), los hombres que pueden hablar con las deidades (ya bădi), las antiguas (ya yógi), los muertos completados (áníma), los muertos que no completaron (ts'ónthï ne ndáhï) y el señor del lugar de los muertos (Zìthü).

\section{Cuerpos habitados}

Para los otomíes, hombres, mujeres y deidades se encuentran habitados por energías que fluyen y les dan vida, denominadas nxúdi, nzáki ne ndáhï, las cuales están contenidas en el cuerpo y algunas de ellas tienen movilidad. Los términos ndähï, que se traduce como “aire” y como "espíritu”, nxúdi como "sombra” y nzáki como "fuerza", muestran varios problemas, debido a que se asocian con diversas cualidades y acciones.

Por ejemplo, nzáki son las figuras de papel recortado y es una entidad anímica. La poseen dioses, plantas, animales y personas. Los otomíes hacen referencia a que nzáki "es un muñeco. Lo van [a] hacer para que tenga mente, como vas a hacer para adivinar algo. Necesitar hacer una persona para tener mente, para trabajar". Se dice que nzáki es una energía que caduca, que se debilita y que se fortalece, que se encuentra distribuida en todo el cuerpo. Cuando la persona envejece y se enferma, nzáki se debilita. Al morir la persona, nzáki se va. Se recorta en papel nzáki de los humanos. Los especialistas rituales tienen nzáki más fuerte. La fuerza o nzáki también está relacionada con la potencia que tienen "las antiguas" para parar o provocar la lluvia, o el poder que mantienen Zìthü'na (señor de los muertos), ya ndáhï y ya ts’ónthï para causar accidentes, peleas, asesinatos y mala ventura. Esta "fuerza" es un elemento que da energía y vida a los humanos (Gallardo Arias, 2012) (véase figura 1).

En el caso de ya ndähï, pueden ser simplemente corrientes naturales. Por tanto, hay aires fríos y calientes que, al entrar al cuerpo, pueden enfermar al individuo; en otras ocasiones, cuando se les llama ya ts'ónthï, se consideran emanaciones asociadas con lo podrido, lo sucio, lo malo u otras cualidades similares. A veces tienen voluntad propia y se activan por sí mismos; en fin, pueden ser entidades malévolas, siendo capaces de tirar al individuo, provocarle susto o incluso robarle su ndáhï o el espíritu. Pero el término ndáhï también es utilizado para referirse a uno de los componentes del cuerpo humano que tiene la capacidad de salirse de él, sobre todo cuando las personas sufren de un espanto y cuando sueñan. Mientras el individuo duerme ni ndähï (su espíritu) vaga por diversas partes y planos de la realidad.

Por último, está nxúdi o "sombra", que alude a los animales que acompañan desde su nacimiento a las personas. Son, en otras palabras, "su sombra". Ya bădi pueden tener 12 animales de aire, 12 animales de tierra. Las sombras de los que habitan el lugar de los muertos (Nídu'na) se asocian con los jaguares y coyotes, animales temidos. Dicen los otomíes que cuando el niño o niña va creciendo también lo hace ni xúdi (su sombra), puede ser un ave o pájaro, "una paloma, un zorrillo, un gato montés, un mono, un jaguar o una víbora", 5 "las personas sueñan que vuelan o que andan por el monte o que se arrastran por las peñas", es así que descifran cuál es el animal que los acompaña durante toda su vida, cuando mueren la sombra se va. ${ }^{6}$

A simple vista, los términos señalados se presentan con un carácter polisémico porque poseen varios contenidos aplicados tanto a los significados (lo que

5 Información obtenida en San Antonio el Grande, municipio de Huehuetla, abril de 2013.

6 Información obtenida en San Miguel, municipio de San Bartolo Tutotepec, noviembre de 2017. 
Figura 1

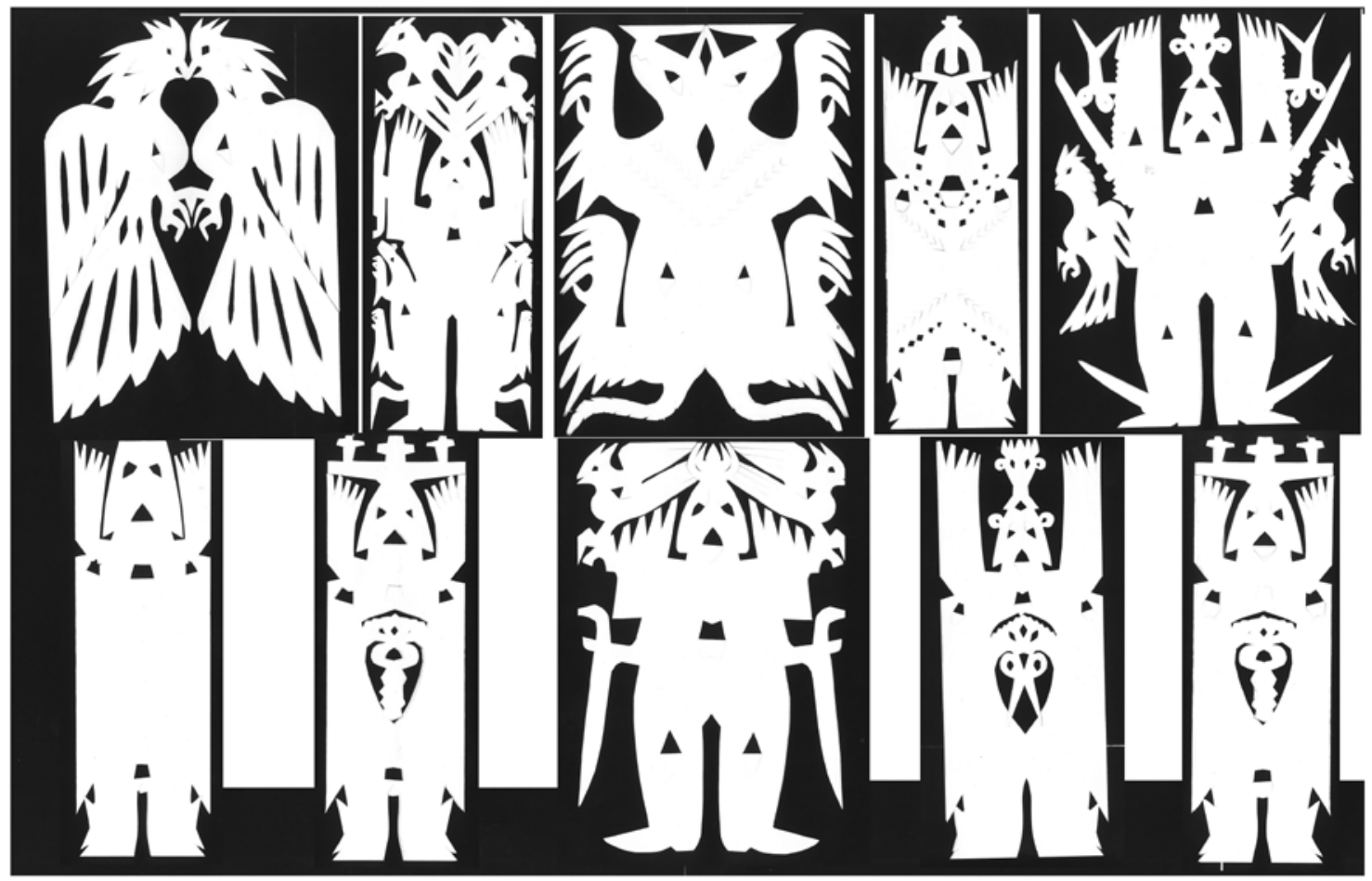

De izquierda a derecha: animales compañeros: águila y jaguar; fuerza del hombre; fuerzas del curandero con tijeras, animales compañeros, sahumerio y campana

se dice de ellos) como a los significantes (animales referenciales). No obstante, encuentran una explicación en la exégesis otomí, como menciona un otomí:

mi pa [el curandero] lo ve con el sahumador o con una vela, [también se puede ver] con un huevo y medio vaso de agua, se les limpia y lo echa allí se ve ndáhï, está dentro del corazón, el alma en la frente, el nzáki es eso para que te dé la fuerza, por ejemplo si la gente está débil se le hace eso del nzáki, para que esté más fuerte y va a andar bien sin pensar nada. El nzáki está dentro hay dos partes abajo del corazón o en la nuca, abajito del corazón, los animales todo lo tienen, maíz tiene también por eso se adora, todo el agua, todo tiene, las piedras, piedras como vidrio o algo así [cuarzos], la tierra, los árboles, la lumbre, frijol, maíz, todo. ${ }^{7}$

Las tres entidades encargadas de proveer al cuerpo y a la persona de diversas características son también las causantes de la enfermedad; por ejemplo, si la persona está decaída o sufre de desmayos, no tiene fuerza, se tendrá que atender su nzáki; si un individuo enferma de "susto", el ndáhï abandona el cuer- po. Testimonio de ello es lo dicho por una curandera: "Cuando morimos se va el espíritu. También se queda en el agua, o cuando tenemos susto, cuando sueña está acostado y sueña que está tirado porque hay alguien que le hace brujería". ${ }^{8}$ Cuentan los otomíes que algunos curanderos mandan su espíritu (ndähï) y su sombra (xúdi) en los rituales para tirar al curandero o curandera que envidian, a veces la sombra no alcanza a hacer el daño a los curanderos sino a sus familiares, quienes caen enfermos.

\section{Cuerpos en construcción}

Los otomíes orientales le dan cuerpo a cada una de las entidades que los habitan, las corporizan no sólo en figuras de papel recortado, sino con máscaras y muñecos de tamaño natural; para este grupo es necesario darle al cuerpo y a las entidades que lo componen peso y forma, para que actúen y dejen de ser sólo potencia y se vuelvan acto (Alvira, 2007). De allí la trascendencia de la formación del cuerpo y su fortalecimiento (véase figura 2).

\footnotetext{
7 Entrevista realizada en la localidad Pie del Cerro, municipio de San Bartolo Tutotepec, agosto de 2007.

8 Entrevista realizada en la localidad de Xuchitlán de las Flores, municipio de San Bartolo Tutotepec, agosto de 2009.
} 
Figura 2

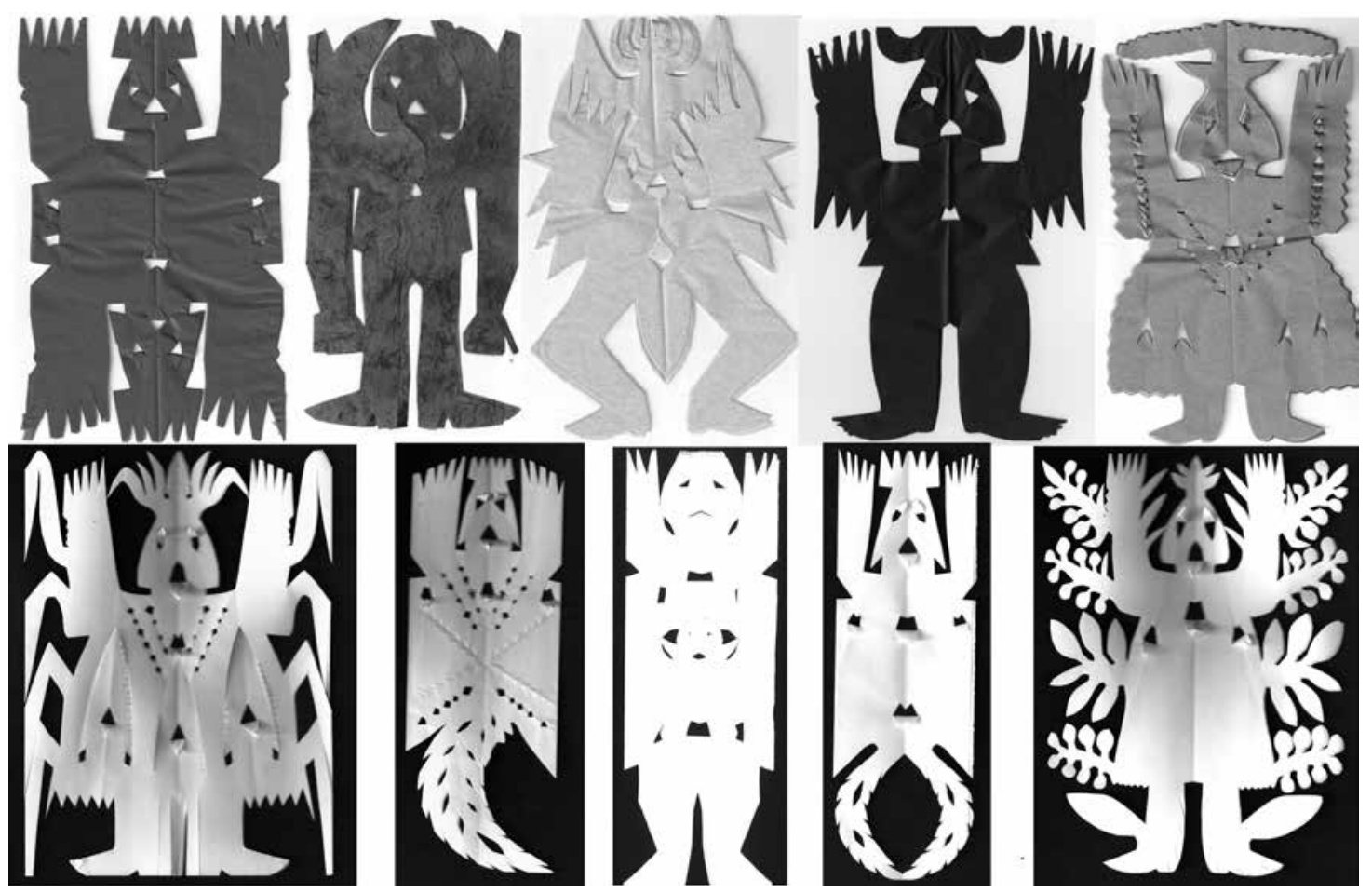

De izquierda a derecha: Xändi ndähi (el que tiene dos cabezas y se multiplica). Ya ts'ónthï (sombra del malo). Xi ngwă ndähï (el que anda "rengo", chiquito pie aire). Hmu nxǔi (señor de la noche). Bêki ndähi (arcoíris). Nzáki Hmú Dethä (fuerza del maíz). Nzáki Hmúthe (fuerza de la sirena). Ximhăi (el universo-mundo). Nzáki Hmúthe (fuerza del señor sirena). Nzáki Hmúda Káfe (fuerza del café).

El cuerpo ${ }^{9}$ del niño o niña es formado gradualmente en la matriz, con el semen o, según algunos otomíes, de una mezcla de semen y sangre menstrual. Durante el embarazo, estas sustancias que son fuente de energía ayudan en la fabricación del feto, "los bebés están amarrados a la madre. Dentro de la panza ya tiene sombra (nxúdi) que crece al mismo tiempo, ya tiene fuerza (nzáki), después cuando nacen se le hace su fuerza para que nadie lo pueda dañar, la fuerza (figura de papel) sólo puede agarrarla el niño". ${ }^{10} \mathrm{~A}$ partir de entonces, este cuerpo es continuamente fabricado por alimentación y reforzado con los rituales. De este modo, los padres tienen y están hechos de la misma esencia del cuerpo de su hijo, ellos dicen que tienen el mismo cuerpo. Pero hay una cuestión más importante: durante el crecimiento, el niño o niña se volverá también consustancial del curandero, quien le hará un ritual para su fuerza; a partir de este acto, niño y especialista tendrán un lazo insoslayable durante toda la vida. Así, cuando el niño crezca y se convierta en adulto, se case, se enferme, el curandero estará a su lado, no su cuerpo sino sus sombras, águilas y jaguares, que corren y vuelan para velar por el bienestar de sus “ahijados”. El especialista es capaz de manipular su ndähï y nxúdi para cuidar y proteger a sus pacientes y parientes rituales (Galinier, 2007: 2). Ahora bien, la proximidad física es muy importante para la consustancialidad, no obstante, sólo se logra a través del ritual.

La formación del cuerpo está ligada al fortalecimiento del nzáki. Los curanderos y curanderas realizan rituales para hacer la fuerza de sus pacientes y de los curanderos que se inician. Se lleva a cabo un ritual donde se llama a las deidades, las que habitan en las peñas y montes y las que viven en grutas y cerros, el bădi recorta el nzáki de 50 cerros a los que se les "llamará" y se les ofrendará para que otorguen sus favores al iniciado y lo fortalezcan; asimismo se recorta el nzáki del fuego, del aire y del agua, además de "la fuerza" de la persona. Para el mundo de los muertos se efectúa una limpia grande "para que el malo" también conceda su protección al principiante. Se invita a participar a dos niños y dos niñas quienes serán los únicos que podrán tocar el agua de las jícaras que se

9 La palabra en otomí para designar cuerpo es Jà’i, mismo término que designa gente y persona.

10 Entrevista realizada en la localidad de San Miguel, municipio de San Bartolo Tutotepec, noviembre de 2017. 
encuentran en el altar. Este ritual incluye ofrendas de comida, ceras, flores y sacrificio de aves. Durante el ritual el altar está lleno de figuras de papel; para los otomíes, estos cuerpos hechos de papel de corteza de árbol poseen una fuerza.

\section{El cuerpo y sus emociones}

Parece evidente que no se puede hablar del cuerpo sin referirse a las entidades que lo habitan, de igual forma, son ellas las que proporcionan al cuerpo sentimientos, emociones, afectos, memoria, pensamientos y conocimiento, también estas entidades son las que le dan inestabilidad al cuerpo, manifestándose en enfermedades.

La memoria, las emociones y la afectividad, dicen los otomíes, se encuentran localizadas en el corazón; éste, más que el órgano, es una zona que abarca la boca del estómago, el esternón y el órgano, a esta región en otomí se le denomina mbǔi (igual término que para estómago), es allí donde se recuerda a la gente, los hechos, la historia del pueblo. La "memoria" es de suma importancia para la constitución del ser humano, para su identidad como miembro del grupo y de su comunidad. No obstante, se tiene que considerar que los humanos no son los únicos que poseen memoria, las deidades la poseen, más que un atributo físico se hace referencia al "corazón" como una forma de ser: envidioso, amoroso, amable, afectuoso, enojón, colérico, como queda expuesto en los rezos donde se enuncian las características del Dämánts'o (el gran malo) o Zìthü (reverenciado muerto, Diablo).

viernes, martes, medianoche, mediodía, siete viernes, siete martes, siete días, siete noches [...], cualquiera que sea yerba, hoja eres, árboles también, tiene corazón, tiene pensamiento, tienes historia, chiflas, cantas, gritas, hablas español, hablas otomí, hablas inglés, tepehua, hablas [como los de] Santana, [en este] mundo, [tú mismo] tienes corazón, tienes tu alma [...], eres mujer mestiza, hombre mestizo, era gente corazón [...], eres mestizo [...], eres mujer de ciudad, eres rico [...], gran juez de este mundo [gran señor] Jefe de los muertos, huesos de los muertos, señor muerte, [de los] muertos [del] mundo. ${ }^{11}$
Memoria y afectividades proveerán al individuo la capacidad para relacionarse con una comunidad, identificarse con un grupo y reconocer una serie de subjetividades incluyendo espíritus, deidades y personas que se transforman en animales (véase figura 3 ).

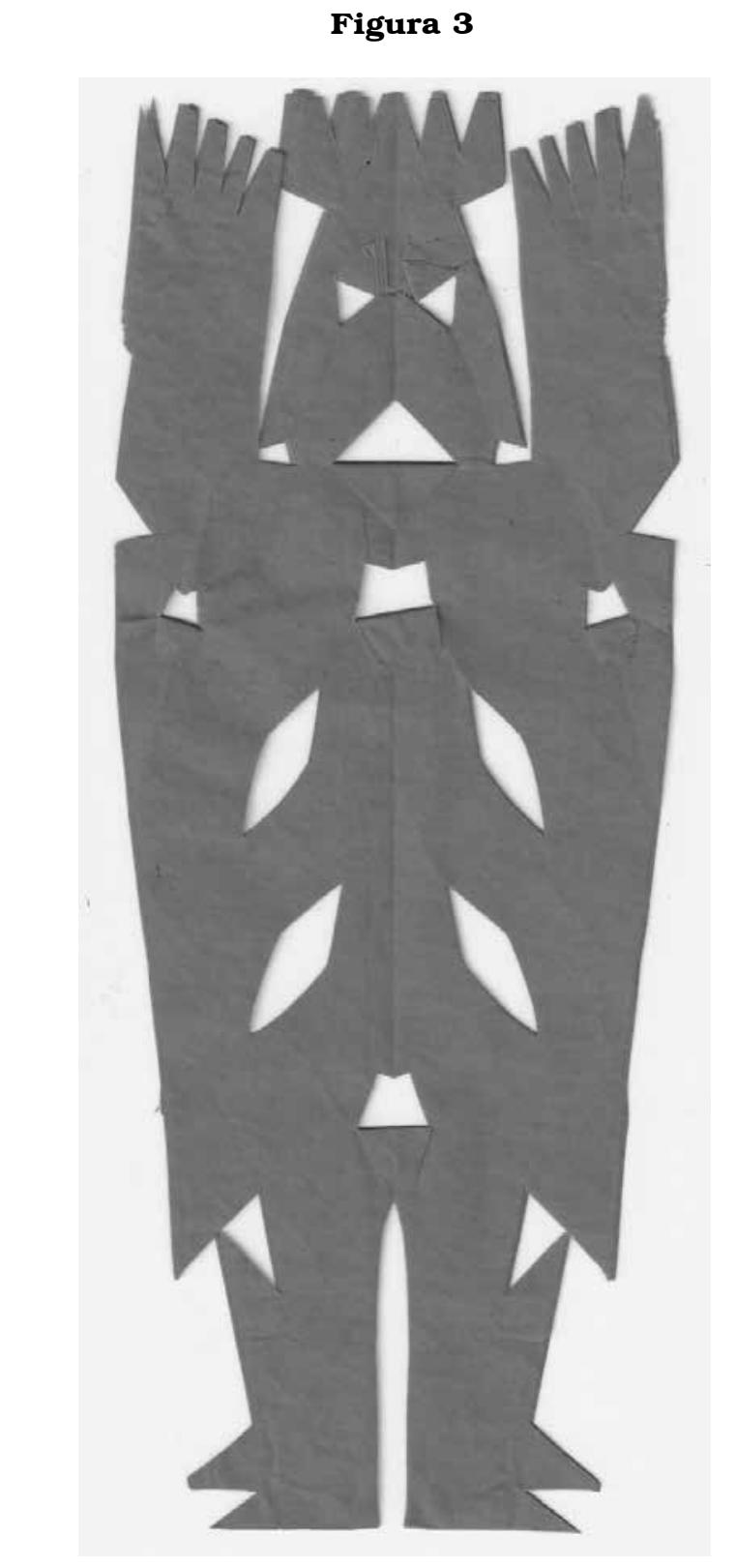

Ts'útabi ndähi (el juez de los espíritus o de los aires)

\footnotetext{
11 "bëhë, martes, ma dexui, uxiadi, yòto bëhë, yòto marte, yòto pa, yòto xui, ana ge bu ana ge ma ge mu dapu, paxi ge mu dapu, hani mui, hani npeni, hani kwentohe, gi hwixt'i, gi túke, gi make, gi mbáke ge ñänpuhe, ñän hñähñu, ga nän tiní, ga ñän Santana, ximhăi, gi seni müi, gi seni peni [...] bi xumpu, nboju nuya ne ka jäi muii [...], ne ka ndesna [...], gu nxumpa, ya gu nboju ya [...], da tsabi ximhăi, da hmú anima, doyo anima, hmu ndate anima ximhăi”. Rezo recopilado en Màyónníja, marzo de 2008.
} 


\section{Cuerpos que cambian}

Los otomíes definen como humano a todos los seres que poseen las tres entidades: ndähï (espíritu), nxúdi (sombra) y nzáki (fuerza), esta última, según se indicó, designa la capacidad de proveer energía vital, así como la facultad de hacer funcionar las cosas, por tanto, implicaría tener conciencia, permitiendo a la persona ser percibida como un similar por otros tipos de seres con capacidad de metamorfosis (hombres y mujeres pueden transformarse en animales, también el señor de los muertos puede cambiar, la deidad del agua puede presentarse con diversos "cuerpos”, como una mujer joven y rubia, como la sirena que habita en las grutas).

En sus estudios de perspectivismo amerindio, Viveiros de Castro nota que cada consideración para ser humano persigue actividades típicamente humanas, por ejemplo tener una vida en familia, realizar rituales, comer y beber (Viveiros de Castro, 2005 y 2004). Compartiendo una misma cultura, la diferencia entre ellos proviene del hecho de que cada clase de ser ve cosas de un modo particular debido a que tiene un cuerpo distinto. Entre los otomíes, los humanos y los dioses son gente, tienen un mismo cuerpo pero no las mismas capacidades, las deidades, al contrario de los humanos, parecen estar potencialmente en todas partes. Los otomíes no conciben al cuerpo como individualizado, pero sus contenidos pueden desprenderse de él, lo que aparece en diversos lugares son su espíritu (ndähï) y su sombra (xúdi), entidades que pueden salirse del cuerpo, por ello, cuando los otomíes dicen que vieron "algo", aluden al espíritu de una persona o a la sombra de una deidad. Igualmente cuentan: "el señor de la noche ( $h m u$ ma xui) es el que anda en las casas luego se va a dejar al monte", ${ }^{12}$ los viejos, los aires malos, los muertos "por la noche andan por todas partes, es más fácil topárselos en cruceros, barrancas, en las peñas, el monte, algunos en el campo santo". ${ }^{13}$

Las deidades también aparecen en los sueños de las personas. Uno de los mayordomos para el carnaval narró que soñó con un viejo que le decía que hiciera la fiesta, pues el mayordomo estaba dudando en comprometerse pues no tenía dinero y en el carnaval se gasta mucho, pero tuvo este sueño y supo que podía realizarla, que sacaría el dinero para ello. Por su parte, una señora relataba que antes no creía en la campana; un día iba al mercado,

en el camino había una mesa con un señor que pedía la cooperación para el costumbre para la campana, yo pensé que no servía de nada así que no dejé dinero y me fui al mercado. Por la noche, cuando dormía soñé que una mujer me decía que tenía que llevar ofrenda, después vi que mi altar estaba lleno de sangre, cuando desperté corrí para dar la cooperación para la campana. Ahora siempre doy ofrenda cuando se hace el costumbre en Tuto para la santa campana. ${ }^{14}$

El espíritu de los muertos vaga por el mundo de los vivos, como expresa don Juan:

Iba yo a Huehuetla. Ya eran como las ocho de la noche, me atravesó un muerto, su pie era largo como la cama. Le digo a mi gente, era un muerto, era aire que estaba, ese muerto era dueño del terreno de allí, también supe que lo mataron. Ese aire si tú tienes miedo es malo, si no tienes miedo no es malo. Si lo encuentras en el camino así tirado tú le dices tú estate allí, le dicen ndähi, porque ése tiene dos ts'ónti, lo que tiene ése espanta, se enchina el cuerpo y como que siente grande su cabeza. Pero yo nunca me espanté, siempre iba solitito a Huehuetla de noche, sólo dos veces lo vi. ${ }^{15}$

Por otro lado, para los otomíes, la capacidad de metamorfosis de los humanos es algo que debe ser controlado, ya que la transformación siempre puede ser el resultado de la agencia de otro, sujeta al deseo del ego; se piensa que los individuos que se convierten en animales lo hacen con el propósito de dañar. Dicen los otomíes que cuando uno va caminando, sobre todo de noche, puede encontrarse al "tigre" (Zàte), que en realidad es un brujo que se transforma en animal y éste se alimenta del espíritu (ndähï) de las personas, robándoselo en el encuentro. Ya Puni (nahuales) "son malos, andan por allí, se transforman y engañan a las personas, andan en el monte como espíritus, se convierten en tigres", ${ }^{16}$ se dedican a hacer maldades y provocar enfermedad (véase figura 4).

El nzáki, nxúdi ne ndáhï son las que hacen posible la interacción entre los humanos y las deidades; estas

\footnotetext{
12 Entrevista realizada en la localidad de San Miguel, municipio de San Bartolo Tutotepec, enero de 2011.

${ }^{13}$ Entrevista realizada en la localidad de Calintla, municipio de San Bartolo Tutotepec, enero de 2009.

${ }^{14}$ Entrevista realizada en la localidad de San Miguel, municipio de San Bartolo Tutotepec, mayo de 2008.

${ }^{15}$ Relato recopilado en la localidad de Calintla, municipio de San Bartolo Tutotepec, enero de 2009.

${ }^{16}$ Entrevista realizada en la localidad de El Kandehe, municipio de San Bartolo Tutotepec, agosto de 2008. Los otomíes utilizan el término Zàte que traducen al español como tigre o jaguar.
} 
Figura 4
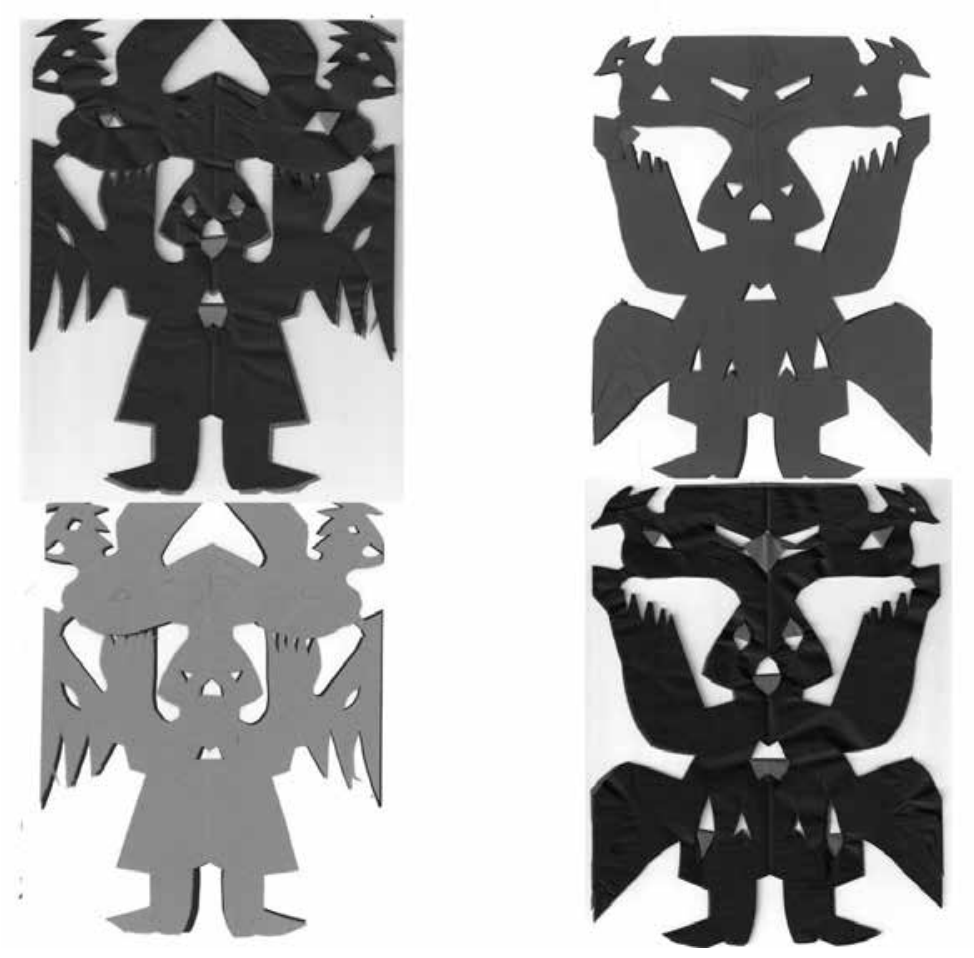

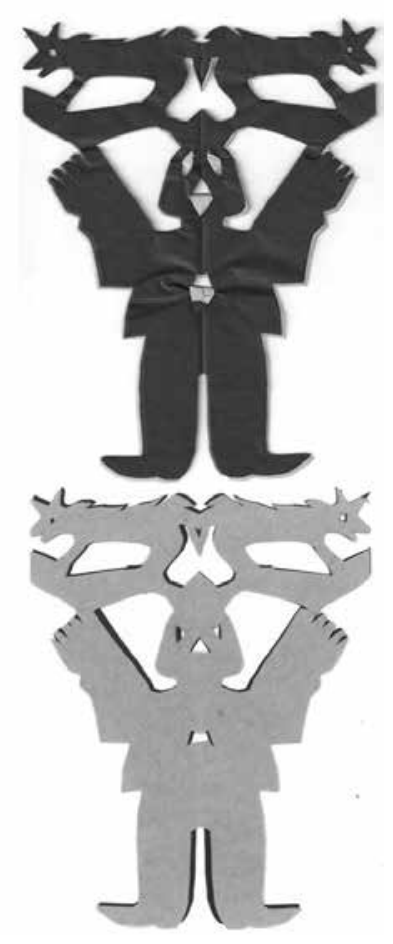

Nxúdi (sombra). De izquierda a derecha: Da’ǔ ndähi (tecolote, ave de mal agüero). Boxki'a ndähi ("gritona”, pájaro negro que grita cuando va a pasar algo, ave de mal agüero). Pǔni ndähi ("sombra del malo", nahuales, hombres y mujeres que cambian de cuerpo, se ahuyentan con las tijeras y el ajo. Andan en el monte como espíritus, se convierten en tigres-jaguares, en coyotes).

entidades permiten que el cuerpo de las personas (junto con su conciencia de ser) sea capaz de percibir las diferencias del mundo de los espíritus de la noche y del mundo diurno o de día. La sangre aparece como la vía para que las entidades cobren fuerza, no el cuerpo sino lo que lo contiene, así, la sangre es el alimento que activa, da fuerza y vitalidad al nzáki, nxúdi ne ndähï. De este modo, el estado humano es potencialmente atribuible a todas las cosas cuando es visto por un ojo bien entrenado. En otras palabras, los especialistas rituales más poderosos son aquellos capaces de subjetivizar el universo entero, localizando la agencia humana en las cosas o su entorno. El bădi ve la sombra de una persona que se convierte en un animal. Los otomíes dicen que mucha gente que ha muerto en ataques de Zàte (jaguares-tigres) en realidad fue asesinada por brujos; lo que las víctimas vieron como un tigre era un brujo que se transformó en animal. Por consiguiente, una roca sólo se hace un objeto de interés cuando es percibido por alguien como un instrumento para dañar. Sin embargo, no hay acuerdo entre los especialistas otomíes para decidir si los animales tienen espíritu (ndähï). De igual forma, los mitos sugieren que el nzáki no es un atributo ontológico fijo, pero sí una capacidad que se vinculó en contextos específicos y primigenios. Algunos objetos de hecho tenían nzáki y lo perdieron por varias clases de desgracia. Por ejemplo, un mito relata cómo los gigantes que existieron antes de los humanos se convirtieron en piedras y cerros cuando apareció el sol. ${ }^{17}$

Todo indica que, para los otomíes, estas intencionalidades (véase Heidegger, 2014) son iguales entre los humanos, los muertos y las deidades. No sólo comparten su condición de "gente" (Jä’i), también los une el fluir de sus contenidos. En el centro de esa visión hay una concepción particular de la interconexión de los humanos con las deidades. Los otomíes destacan como centro del cosmos el cuerpo y sus contenidos, tal como se manifiestan en el término nzáki, fuerza

\footnotetext{
${ }_{17}$ San Antonio el Grande, municipio de Huehuetla, 2013; El Kandehe, 2012 y Pie del Cerro, 2008, municipio de San Bartolo
} Tutotepec. 
que da vida a seres humanos y a deidades, principio vital y realidad trascendental, más allá de toda diferenciación física que une a los humanos con las deidades. De esta manera, el ritual es interpretado como intercambio: ofrendar es un acto regenerativo a través del cual la muerte sirve para la regeneración de la vida. Las deidades son tratadas por ya bädi como iguales y como personas, sobre todo las que habitan el inframundo, socios en un pacto moral que gobierna las relaciones dentro de la sociedad humana. La vida humana tiende a ser una meta única, fundamental y socialmente valorada: mantener y reproducir la totalidad interconectada de los vivos con los muertos para preservar el mundo, para que "la vida siga". De hecho, esta responsabilidad cosmogónica hacia el Todo recae en los especialistas, quienes son capaces de hablar con las deidades.

La noción de gente (con calidad de humanidad) entre los otomíes es una condición que se extiende a varios tipos de seres: el señor de los muertos, las señoras de las semillas, del agua, del fuego, de la tierra y hasta la misma campana. Sin embargo, se alude a la diferencia en los seres por medio de la categoría "nosotros" en oposición "a ellos" y sus contenidos (Nzáki, nxúdi, ndähï) e intensidad son variables. Los otomíes piensan que la oposición humano/no humano no es determinante para entender las diferencias de seres que habitan el universo. Sería entonces la ontología misma (de lo que está compuesto el ser) la clave de entendimiento en el caso otomí.

\section{Consideraciones finales: cuerpos inestables}

Como se analizó con anterioridad desde la perspectiva de Bourdieu, la correspondencia entre las estructuras sociales y mentales tiene su justificación en lo más profundo del cuerpo, donde se interiorizan los esquemas del habitus. Es decir, el cuerpo en la teoría de Bourdieu es un cuerpo socializado, un cuerpo estructurado, un cuerpo que se ha incorporado a las estructuras inmanentes de un mundo. El cuerpo es, de este modo, condicionado por la sociedad, modelado por las circunstancias materiales y culturales de existencia en las que está colocado desde el origen. Teniendo en cuenta que se trata siempre de cuerpos "socializados" se puede decir que hay un segundo punto de vista, inseparable del primero: las instituciones. La historia hecha naturaleza es historia hecha cuerpo por la educación. Cabe aclarar que la mayor parte de esta transmisión se hace "en estado práctico", o sea, sin enunciación, sin explicitación, sin acceder al nivel discursivo. Esta inexplicitación de las prácticas constituye un aspecto esencial que va a dar su forma particular a la lógica subyacente. Aprehender no es comprender, sino incorporar, introducir en el cuerpo. Lo que se aprende por el cuerpo no es algo que se posee, como un saber que uno pueda mantener delante de sí, sino algo que se es (Bourdieu, 2007: 105-128; 1997: 179, 193-195). Es así que la composición corporal hace visible una manera específica de hablar, de caminar, y por eso de sentir y de pensar; en síntesis, de ser. Se puede entender, por lo tanto, la representación corporal como un proceso regidoy determinado por un sistema de valores, un discurso social constituido por ciertas reglas, tradiciones, hábitos, creencias y prácticas culturales.

Uno de los rasgos principales del cuerpo es su vulnerabilidad. La subjetividad es una cuestión de refracción que cobra sentido en las percepciones que otros tienen sobre mí, así, la individualidad es un estado cuya naturaleza resulta sumamente inestable, ya que está formado por lo que otros perciben y piensan de mí; la individualidad estaría medida por la intersubjetividad (Taylor, 2000). Si es de este modo, cualquier desequilibrio externo hace a la persona vulnerable. Esta vulnerabilidad con frecuencia se traduce en enfermedad. De allí deriva que la inestabilidad del cuerpo y sus contenidos no sea sólo el resultado de encuentros impresionantes en el monte con los espíritus y sombras de los dueños de lugares, de los brujos o el diablo, sino también de un aspecto intrínseco de las relaciones internas en la comunidad. En la sierra otomí se procura no pelear ni estar en desacuerdo con los vecinos, sobre todo con los especialistas rituales quienes curan las enfermedades, pero que de igual manera las pueden provocar. Dependiendo de la percepción que el otro tenga sobre uno mismo es que la propia autoimagen producirá un alto grado de vulnerabilidad. De cualquier forma, la percepción del cuerpo será una imagen construida por los otros, una imagen condensada de emociones, afectos, enfermedades, virtudes y defectos. La fragilidad generada por la precariedad del cuerpo, como especifica Taylor, puede ser resuelta mediante los rituales, así como por la curación por medio de procedimientos terapéuticos con los especialistas rituales. Para los otomíes, el cuerpo es continuamente fabricado, se va construyendo durante la vida de un ser humano, se va habitando de entidades que lo animan (que lo identifican), valores culturales, ritos y mitos. Podría decirse que el cuerpo es una construcción social y depósito de la historia del grupo.

Se puede concluir que la idea de un cuerpo en constante fabricación contiene en sí misma la noción 
de transformación, de construcción; así, un cuerpo nunca es algo terminado; la etnografía permite dar cuenta de que lo que los otomíes conciben como gente está determinado por lo que ellos conciben como universo, de allí varios aspectos cobran relevancia para determinar el cuerpo: la noción de transformación, metamorfosis, humanidad, entidades anímicas, fuerza, inestabilidad, equilibrio, enfermedad y potencialidad.

\section{Fuentes}

\section{Alvira, TOMÁs}

2007 El significado metafísico del acto y la potencia en la filosofía del ser, Universidad de Navarra, Navarra, $46 \mathrm{pp}$

Boilés, Charles

1971 "Síntesis y sincretismo en el carnaval otomí", en América Indígena, vol. 31, núm. 3, pp. 555-563.

BOURDIEU, PIERRE

1997 Razones prácticas. Sobre la teoría de la acción, Anagrama, Barcelona, 233 pp.

Bourdieu, Pierre

2007 El sentido práctico, Siglo xxi Editores, Buenos Aires, $456 \mathrm{pp}$

Cabrera, Paula

2014 "Propuesta teórico-metodológica para el estudio de la subjetividad desde una perspectiva antropológica”, en Virajes, vol. 16, núm. 1, enero-junio, pp. 185-208.

ECHEGOYEN, ARTEMISA

y CATHerine Voigtlander

2007 Diccionario Yuhú. Otomí de la Sierra Madre Oriental. Estados de Hidalgo, Puebla y Veracruz, Instituto Lingüístico de Verano, México, $634 \mathrm{pp}$.

Foucault, Michel

1991 Saber y verdad, La Piqueta, Madrid, 245 pp.

Foucault, Michel

1992a Microfísica del poder, La Piqueta, Madrid, 189 pp.

Foucault, Michel

1992b Historia de la sexualidad. 3. La inquietud de sí, Siglo xxi Editores, México, 169 pp.

Galinier, Jacgues

1990 La mitad del mundo. Cuerpo y cosmos en los rituales otomíes, Universidad Nacional Autónoma de México/Instituto Nacional Indigenista/ Centro de Estudios Mexicanos y Centroamericanos, México, $746 \mathrm{pp}$

Galinier, JaCQUes

2007 "Equilibrio y desequilibrio en el cosmos. Concepciones de los otomíes orientales", manuscrito.
Galinier, Jacgues

2009 El espejo otomí. De la etnografía a la antropología psicoanalítica, Instituto Nacional de Antropología e Historia/Comisión Nacional para el Desarrollo de los Pueblos Indígenas / Centro de Estudios Mexicanos y Centroamericanos, México, 214 pp.

Gallardo Arias, Patricia

2012 Ritual, palabra y cosmos otomí, yo soy costumbre, yo soy de antigua, Universidad Nacional Autónoma de México-Instituto de Investigaciones Históricas, México, 130 pp.

HABERMAS, JÜRGEN

1987 Teoría de la acción comunicativa II. Crítica de la razón funcionalista, Taurus Humanidades, Madrid, $618 \mathrm{pp}$.

HeidegGer, Martin

2014 Ser y tiempo, Trotta, Madrid, $490 \mathrm{pp}$.

LÉVY-BRUHL, LUCIEN

1996 L'âme primitive, Quadrige/Presses Universitaires de France, París, 451 pp. [1927].

López Austin, Alfredo

1996 Los mitos del tlacuache, Universidad Nacional Autónoma de México-Instituto de Investigaciones Antropológicas, México, 158 pp.

MAUSS, MARCEL

1985 "Les techniques du corps", en Sociologie et anthropologie, Quadrige/Presses Universitaires de France, París, pp. 365-386 [1936].

TAYLOR, ANNE-Christine

2000 "Corps immortels, devoir d'oubli: formes humaines et trajectoires de vie chez les Achuar", en M. Godelier y M. Panoff (eds.), La production du corps: approches anthropologiques et historiques, Éditions des Archives Contemporaines, Ámsterdam, pp. 317-338.

TURNER, VICTOR

1980 La selva de los símbolos, Siglo xxI Editores, México, $455 \mathrm{pp}$.

Viveiros de Castro, Eduardo

2004 "Perspectivismo y multinaturalismo en la América indígena", en A. Surallés y P. Hierro (eds.), Tierra adentro, International Work Group for Indigenous Affairs, Copenhague, pp. 37-81.

Viveiros de Castro, Eduardo

2005 "Chamanismo y sacrificio: un comentario amazónico”, en Jean-Pierre Chaumeil, Roberto Pineda y Jean-François Bouchard (eds.), Chamanismo y sacrificio. Perspectivas arqueológicas y etnológicas en sociedades indígenas del sur, Instituto Francés de Estudios Andinos, Bogotá, pp. 335-347.

Viveiros de Castro, Eduardo

2009 "El Diablo en el cuerpo (a propósito de La moitié du monde: le corps et le cosmos dans le rituel des indiens Otomi, de Jacques Galinier), en Dimensión Antropológica, año 16, vol. 46, mayo-agosto, pp. 47-69. 